\title{
ORDO RERVM MATHEMATICARVM QVAE ELEMENTORVM LIBRIS 1-4 CONTINENTVR
}

Libro primo XXIII definitiones, V postulata, IX communes animi conceptiones, XLVIII propositiones continentur. ex quibus XXVI primae ad constructionem et proprietates rectilineorum segmentorum angulorum et triangulorum pertinent. reliquae XXVII-XLVIII ad parallelas rectas, ad parallelogramma eorumque proprietates et ad transformationem rectilineorum segmentorum spectant. praecipue propositione XLIV, quo modo construatur parallelogrammum, demonstratur.

Liber secundus II definitiones et XIV propositiones continet. ex quibus decem primae ad aequalitates algebraicas spectant, quas mathematici nostrae aetatis Pythagoream algebram vocant. undecima est de recta secundum extremam et mediam rationem secanda, proportionibus non adhibitis. duodecima et tertia decima ad theorema, quod hodie theorema cosinus vocatur, pertinent; quarta decima transformationem rectilinei segmenti in quadratum demonstrat.

Libro tertio XI definitiones et XXXVII propositiones, quae ad circulum spectant, continentur.

Liber quartus VII definitiones et XVI propositiones continet, quibus de inscriptione ct circumscriptione regularium multangulorum in circulum agitur.

\section{XXXIV}

